\title{
Care handover to chronic conditions to regionalized planning
}

\author{
A transição do cuidado às condições crônicas face ao \\ planejamento municipal regionalizado \\ La transición del cuidado orientado a condiciones \\ crónicas en el planeamiento regionalizado
}

\section{Kamila da Silva Pena \\ Rosane Machado Rollob \\ Camila Luana Oliveira Reuter ${ }^{c}$ \\ Vilma Constancia Fioravante dos Santos ${ }^{\mathrm{d}}$ \\ Deise Lisboa Riquinhoc \\ Adriana Roese Ramos ${ }^{c}$}

How to cite this article:

Pena KS, Rollo RM, Reuter CLO,

Santos VCF, Riquinho DL, Ramos AR.

Care handover to chronic conditions

to regionalized planning. Rev Gaúcha

Enferm. 2020:41(esp):e20190168.

doi: https://doi.org/10.1590/1983-

1447.2020.20190168 a Hospital de Clínicas de Porto Alegre (HCPA). Porto Alegre, Rio Grande do Sul, Brasil.

b Universidade Federal do Rio Grande do Sul (UFRGS), Programa de Pós-Graduaçãa em Educação. Faculdade de Educação, Porto Alegre, Rio Grande do Sul, Brasil.

c Universidade Federal do Rio Grande do Sul (UFRGS), Escola de Enfermagem. Porto Alegre, Rio Grande do Sul, Brasil.

'Faculdades Integradas de Taquara (FACCAT), Departamento de Enfermagem, Taquara, Rio Grande do Sul, Brasil.

\section{ABSTRACT}

Objective: To analyze the possibilities of the transition from care to the problem of chronic illness due to the need of regionalized municipal planning.

Method: An exploratory qualitative study was carried out in one of the Health Regions of Rio Grande do Sul, together with the Primary Health Care Coordinators.

Results: The final thematic categories that emerged from the results were: "The relationship between municipalities of the Health Region and health planning", Organizational flow of care of users with chronic diseases", and "Managing care in the health system: meeting the demands of chronically sick users".

Conclusions: The scenario under study demonstrates the persistence of barriers that affect health care for NCDs, such as the scarcity of investments, lack of planning and disarticulation of communication among municipalities. These conditions reflect on the path of the user among the health services, weakening the transition process of care.

Keywords: Transitional care. Regionalization. Health planning.

\section{RESUMO}

Objetivo: Analisar as possibilidades da transição do cuidado diante da problemática do adoecimento crônico face à necessidade do planejamento municipal regionalizado.

Métodos: Estudo exploratório de abordagem qualitativa, realizado entre o segundo semestre de 2014 e o primeiro semestre de 2015, em uma Região em Saúde do Rio Grande do Sul junto aos Coordenadores da Atenção Primária em Saúde. A análise dos dados se deu por categorização temática.

Resultados: As categorias temáticas identificadas foram: "A relação entre os municípios da Região em Saúde e o planejamento em saúde", "Fluxo Organizacional de atendimento ao adoecido crônico" e "A gestão do cuidado na rede de atenção: o movimento de atender a demanda dos adoecidos crônicos".

Conclusões: Demonstra-se a persistência de entraves que afetam a atenção em saúde às Condições Crônicas Não Transmissíveis e se refletem na trajetória do usuário entre os serviços de saúde, fragilizando o processo da transição do cuidado.

Palavras-chave: Cuidado transicional. Regionalização. Planejamento em saúde.

\section{RESUMEN}

Objetivo: Analizar las posibilidades de la transición del cuidado ante la problemática del enfermo crónico ante la necesidad de la planificación municipal regionalizada.

Método: Estudio exploratorio de abordaje cualitativo, realizado en una de las Regiones en Salud de Rio Grande do Sul junto a los Coordinadores de la Atención Primaria en Salud.

Resultados: Las categorías temáticas finales que surgieron de los resultados fueron: "La relación entre los municipios de la Región en Salud y planificación en salud", "Flujo Organizacional de atención al enfermo crónico”y“La gestión del cuidado en la red de atención: el movimiento de atender la demanda de los enfermos crónica".

Conclusiones: El escenario en estudio demuestra la persistencia de trabas que afectan la atención en salud a las CCNT como la escasez de inversiones, insuficiencia en la planificación y desarticulación en la comunicación entre los municipios.

Palabras clave: Cuidado transicional. Regionalización. Planificación en salud. 


\section{INTRODUCTION}

In Brazil, the discussion on coordinated and organized health care models has gained space in the academic literature and legislation, mainly due to chronic illnesses and the necessary sustainability of the health system ${ }^{(1-2)}$.

The perspective of care coordination proposes that community, assistance, and managerial resources be interconnected to enable intervention in complex situations, as in the case of chronic conditions, in which users require the simultaneous and prolonged use of different health care resources ${ }^{(1)}$. However, in view of the economic conjuncture of fiscal austerity, the role and intervention of the State in health care have progressively diminished. This scenario in health services provision has affected the health condition of people, especially with regard to patients with chronic diseases ${ }^{(3-5)}$.

Thus, this context generates an increasing demand for efficient public management and collaborative mechanisms that support users of the health services and ensure their needs are met. These improvements are needed despite the persistent limitations in municipal, regional, and state planning ${ }^{(6)}$.

The macro-organizational field of the health care system has institutionalized provisions for shared management tools, as in the case of the political-administrative organization of the Health Regions based on the cultural characteristics and capacity of the federal bodies ${ }^{(2)}$. In view of the institutionalized recommendations for ways to manage health care provision, other forms of organizing local health systems are also emerging, according to the concept of Health Region coined in Decree 7.508/2011. One of the possibilities is organizing the municipalities in a systemic and coordinated way to establish what is known as Regionalized Municipal Planning to ensure municipalities become solidary and cooperative in health care for chronic users, within the context of Health Regions, either from the perspective of primary care or medium or high complexity care $^{(6)}$. Consequently, municipalities could share experiences, challenges, resources, and obstacles and promote exchanges, organize strategies, and interconnect and horizontalize municipal and regional relations of the health system.

The connection between primary care and the services of other care levels, promoted by the municipalities in the Health Region, is fundamental for users to adhere to their therapeutic plan, resulting in positive results for the population ${ }^{(7)}$. When this link is not achieved, the planning of health services and communication between the services are weakened. Moreover, the absence of this link prevents the transition of care from occurring, which affects those who need this strategy to access quality health care actions ${ }^{(8)}$.

Based on the need to organize and coordinate care in the health system, it is also necessary to reflect on the transition of care due to the increasing demands related to the epidemiological transition and the prevalence of chronic diseases. Chronic conditions require the health systems to propose strategies that reduce the length of hospital stays and better qualify care to the community. The transition of care and the actions involved are important to overcome the fragmentation of health care and ensure the continuity of care ${ }^{(9-10)}$. Although the coordination of hospitals with the other health services supports implementation of better practices and allows the continuation of post-discharge care, it is still a rare activity ${ }^{(11)}$ that could be possible through the proposal of Regionalized Municipal Planning.

The transition of care is defined as a set of actions that ensure coordination and continuity of health care when users are transferred from one service to the other or between different units in the same health service ${ }^{(12)}$. This strategy ensures the longitudinality of assistance and the continuity of care after discharge, which improves the quality of life of patients, helps prevent readmissions, and reduces costs (10-13). $^{(13)}$.

The discussion of the transition of care prescinds from the discussion of the organization of municipalities in a broader sense, here proposed according to administrative organization into Health Regions ${ }^{(2)}$ and the complex relationships between the municipalities that constitute these regions, based on the image-objective of the Regionalized Municipal Plan ${ }^{(6)}$. In view of the above, the present study sought to answer the following question: What are the possibilities of care transition given the problem of chronic illness due to the need for regionalized municipal planning? Thus, the aim of this paper was to analyze the possibilities of transitioning care given the problem of chronic illness in relation to the need for regionalized municipal planning.

\section{$\square$ METHODS}

This is qualitative, exploratory study ${ }^{(14)}$ conducted in the state of Rio Grande do Sul, in the municipalities of Alvorada, Cachoeirinha, Glorinha, Gravataí, in Porto Alegre and Viamão in Rio Grande do Sul, which comprise Health Region 10. The region was chosen because of the challenges of organizing the health care network in large cities, especially in relation to chronic illness.

The primary care coordinators of the aforementioned municipalities participated in this study. At the study 
locations, this management position was mostly occupied by nurses. Of the nine professionals interviewed, eight were nurses and one was a physician. One of the municipalities had two primary care units, while, in two other municipalities, in addition to the primary care coordinators, two coordinators of the health departments participated in the study, totaling nine interviewees. The interviews were conducted between the second semester of 2014 and the first semester of 2015 after scheduling and previously agreeing on the day and place by telephone or email with the coordinators.

The questions were related to the organization and management of non-communicable diseases (NCDs) in primary care regarding the use of electronic medical records and singular therapeutic plans, meetings between municipalities to discuss the inter-municipal use flow of health services, and the strategies adopted by the primary care unit to meet the daily challenges of organizing the services. The interviews were recorded and transcribed in full into a Word document for content analysis ${ }^{(14)}$. For the thematic categorization, NVivo 9 software was used in three stages, namely pre-analysis, exploration of the material, and processing of results and interpretation ${ }^{(14)}$. The analysis units emerged from the thematic analysis and they were organized into the analytical categories presented in the Results section. The interviewees were coded as ECAB - interviews with managers, from one (1) to nine (9). Considering the proximity of the management activities, the same code was used for the other two coordinators of the health department, included at the request of the primary care units.

The bioethical considerations were observed, as specified in Resolution 466, of December 12, 2012, of the National Health Council ${ }^{(15)}$. The respondents received and signed an informed consent statement to confirm they accepted to participate in the study and were guaranteed anonymity. This study was approved by the research commission of the Escola de Enfermagem da Universidade Federal do Rio Grande do Sul (UFRGS), by the ethics committees of the UFRGS, and by the municipal department of health of Porto Alegre, under numbers 708.357/2014 and 885.916/2014, respectively.

This paper is part of the study entitled "Doenças crônicas não transmissíveis e o planejamento em saúde: os desafios da região metropolitana Porto Alegre-RS", financed by the Fundação de Amparo à Pesquisa do Rio Grande do Sul (Fapergs) in partnership with the Ministry of Health (MS), the Conselho Nacional de Desenvolvimento Científico e Tecnológico (CNPQ) of Brazil and the state department of Rio Grande do Sul Health/ SES-RS within the scope of the Programa de Pesquisa para o SUS: gestão compartilhada em saúde (Unified Health System research programme: shared management in health), under public call FAPERGS/MS/CNPq/SESRS 002/2013.

\section{RESULTS}

The final thematic categories that emerged from the results were the following: "The relationship between municipalities of the Health Region and health planning", Organizational flow of care of users with chronic diseases", and "Managing care in the health system: meeting the demands of chronically ill users".

\section{The relationship between municipalities of the Health Region and health planning}

Given the growing demand in health, the municipalities of the region under study have been structured to discuss the organization and planning of health care in the municipalities and in the Health Region. In this movement, meetings are held between the health coordinators to discuss planning of the Health Regions and the local organization of the municipalities in relation to the service offered to the users.

The contact happens. We have the Regional Coordination forums [...] where we participate with another coordination and discuss extensively. (ECAB8)

However, it was emphasized that the communication and participation of municipalities are based on specific demands, mainly to qualify programmatic actions already implemented or update public health policies implemented transversally.

When a topic such as STD, AIDS, or mental health is addressed, they bring together the regional units, they have some policies that really make the meeting with the regional area happen, to think about the situation. Or, when a new decree is launched, some new ordinance [...]. (ECAB3) Once a month, they gather the municipalities and talk about topics that are popular at the time. Between meetings, we choose a theme, "Oh, next month we will talk about the stork network that has stopped", then all the municipalities say, "I am doing that, this, or the other" [...]. (ECAB9)

\section{Organizational flow of care of users with chronic diseases}

Regarding the organizational flow of care, it was verified that users constantly transition between municipalities, both due to the geographic proximity between them and the choice of people for specific services, such 
as medium and high complexity, according to individual interests and the availability of installed capacity. One of the interviewees points out that the city has a reputation for efficiently processing all referrals.

We serve neighboring municipalities; users live in other cities and have relatives here, they get light bills with the address of relatives, who write a statement and sign, if they need to register at the registrar, they will take it [...]. (ECAB5)

The demand here is smaller than in the neighboring municipality, so they know that the service is faster, the referrals are faster, everything ends up being faster. So they end up coming here and create a bond, a link. Patients we have had for years we know do not live here. (ECAB6)

One of the critical points faced by users with chronic diseases is the waiting time to receive care in medium and high complexity care. This problem can be solved by qualifying information in the referral forms so primary care workers do not distance themselves from the care once users enter the regulation system because they can no longer access the referral system, which is the responsibility of the regulatory sector of the municipalities.

We have tried to improve the issue of qualifying the referrals [...] The less specific, the less clear it is, the more it will take [...] it usually works like this: the user leaves the basic health unit with a referral, comes to the municipal health department and is entered into the system [...] The same person brings it and the department of control, auditing, and evaluation is responsible for responding and providing an appointment date. (ECAB9)

The municipalities have the organizational difficulty of meeting the demands that originate from judicialization, which is an alternative for users who have problems accessing the health services.

[...] The user resorts to another alternative that is judicialization [...] Sometimes, when access to health care is difficult for users, access is no longer primary care, it is legal means, justice. (ECAB7)

The municipalities can expand the installed capacity with the financial resources offered by the Ministry of Health and state departments, which is a choice of the public agenda of these spheres. In reality, it was found that the possibilities of increasing the supply of health services involve hospital beds and emergency care units.
[...] they are also building an ER unit to relieve the pressure of the hospital a little. In relation to chronic diseases, in the part of admissions, the hospital is being expanded [...] This, it was in the dispute of the regional hospital, the municipalities that entered the dispute, they got an outbuilding. [...] So it will relieve the overcrowding in Porto Alegre quite abit. (ECAB2)

Another respondent mentions the difficulties the municipalities have in financing health actions due to the insufficient investments of the State and Union.

The city, as incredible as it seems, invests more here than the institutional minimum that I think is twenty-five percent for health. The municipalities feel very isolated in this part of funding. Because there is none, if we started buying all the specialized services that are lacking at state level, at national level, we would fail, there is not enough money. [...]. (ECAB7)

\section{Managing care in the health system: meeting the demands of chronically ill users}

The interviewees state that they perform health actions for users with chronic illnesses, through group activities for hypertensive and diabetic patients, and activities at the users' homes with the community health agents. Another element the municipalities still provide are campaigns and programmatic actions for specific populations, such as actions for women's health and men's health.

There are groups in all units, they have hypertensive and diabetic patient groups. Some have managed to implement groups for mental health, the community agents do the work at the patient's home. (ECAB2)

We have some annual schedules of the municipality, women's health [...] We started last year with a men's health campaign, which was new, and in November, we made it blue November, which is a preventive campaign to bring men into the units [...] it was quite positive in some places. (ECAB1)

The institutionalized spaces of health promotion initiated an interdisciplinary movement for the self-care education of users involving professionals from different areas and sectors. The interviewees report actions involving food and medication associated with conventional health prevention.

We provide medication and food guidelines. From time to time, the pharmacist attends the group sessions and 
lectures on medication [...] We have a nutritionist too, who belongs to the department of education, who has sometimes helped us. She goes to the group sessions and talks with the patients and the nurses do the rest [...]. (ECAB4)

The interviewees show that users, even after being referred to more complex services, remain linked to the primary care service.

[...] The patients return to primary care, they do not continue to another service. (ECAB7)

Although the link to primary care remains, the primary care units report that users are not opposed to being referred to other services, which fragments and hinders the required care actions.

No, itdoes notexist [...] The patient always leaves with the guidelines but not with a counter-referral to the professional. (ECAB3)

[...] The counter-referral, as in all locations, is very difficult. (ECAB7)

[...] counter-referral, it is very rare. Usually, they get the procedure or exam done in the other municipality and return appointment when they are ready [...] they do not get the return appointment.. (ECAB2)

Because of this problem, one of the interviewees mentions the electronic medical record as a positive tool to qualify counter-referrals. The electronic medical record would help fill loopholes and facilitate communication between the different levels of care.

This I think is an issue that we need to qualify. I think this qualification will only occur with the use of computers [...] With the electronic medical record, when you enter the referral, it requires you to add items in order to classify[...] the counter-reference itself needs to report this. When you have the electronic medical records, the physician at the specialty center will enter the report into the medical records, and when patients come back, the doctor's report is already included. So for me, today, the only solution comes from the electronic medical records with continuous access. (ECAB8)

The interviewees perceive the need to provide care for extended periods, especially in primary care, but indicate that economic-financial obstacles limit the expansion of coverage and care.

We know it would be very important to extend the time of appointments and pharmacy, but the municipality does not have enough professionals and we cannot hire any because we are at the limit of the tax liability law. [...]. (ECAB2)

In the studied Health Region, municipalities mainly focus their installed capacity on primary care and medium complexity services. One of the managers points out that most of the population depends on public health services, that is, primary health care, so the restricted working hours affect many people.

Here in the city, $98 \%$ of people use the Unified Health System, so 2\% have medical insurance. The city is almost exclusively dependent on the Unified Health System. (ECAB1) [...] sometimes the users miss an appointment with a specialist because they do not have the bus fare money, and this is not a reality, this is almost a day-to-day issue. (ECAB8)

\section{DISCUSSION}

The movement of municipalities in discussing the use flow of people in political spaces, such as the regional coordination forums, is an important advance in the care provided to patients with chronic diseases within the perspective of Regionalized Municipal Planning. Although these debates are still restricted to specific demands, one can see an attempt by the municipalities to share experiences and obstacles to the inter-municipal and regional coordination of care, thus providing solidary exchanges regarding different levels of care in the Health Region ${ }^{(6)}$. This finding should be discussed considering the complexity of chronic illness, the need to centralize primary care in the coordination of care, and the power of establishing strategies that favor the transition of care ${ }^{(1,9)}$, such as those mentioned above. The demands of chronic conditions require health care services and networks to structure mechanisms based on the user's perception of their health status and reinforce the family's participation to achieve greater visibility on the subject ${ }^{(16)}$.

In the studied scenario, it was verified that the communication problem persists between primary care, other levels of care, and the municipalities of the Health Region, in addition to the delay in assistance in medium and high complexity care, which weakens the capacity of the regionalized health system to support the municipalities. One of the paths found by the municipal managers was to qualify case management although this option is far from the recommendation because the information is not shared among the care levels and the municipalities of the same Health Region, as specified in Decree 7.508 (2). Consequently, users with chronic diseases have difficulty accessing the health care they need ${ }^{(7-9)}$. 
It is believed that if the municipalities of the same region are organized jointly in the care network and bring primary care routines together, health care, especially for users with chronic diseases, will be qualified and processes will be optimized based on the successful experiences of neighboring municipalities. The region is brought together because of its cultural, economic, and social identity, as mentioned in the concept of Health Region in Decree $7.508 / 2011^{(2)}$.

In this context, it is worth noting that there are still tensions that impose the user's health demand on municipal management through judicialization. This causes the planning of municipalities to be deprecated in the name of punctual, albeit indispensable demands, from the point of view of the right to health care. Consequently, it is necessary to address regionalization and provide spaces to discuss information on municipal, regional, and state planning and the organization of referral flow among health care services ${ }^{(1)}$. Furthermore, care for users with chronic diseases must be linked and longitudinal in order to include the different levels of care and referred municipalities for effective case management. The transition of care must be transferred to the different levels of care and forms of organization of local and regional health systems.

The political conjuncture of fiscal austerity ${ }^{(3)}$ imposes additional difficulties on the municipalities, considering that chronic conditions require extended health care and a change in the care model| ${ }^{(8,17)}$. However, in the present study, the municipalities have limited resources offered by the State to meet the demands of chronically ill patients. The insufficient resources of the Unified Health System and the allocative inefficiency means resources deviate to medium and high complexity care. Scarce investments in primary care and, consequently, in actions related to NCDs reduce the possibility of positive outcomes and aggravate the condition of chronically ill patients $s^{(5,17)}$.

Given these limitations, attempts have been made to provide an interdisciplinary nature to care management based on the link with primary care. However, the health services of the care network do not communicate ${ }^{(18)}$, hindering Regionalized Municipal Planning. Evidence shows it is impossible to provide effective, efficient, and quality care without powerful clinical information systems. Information technologies reduce costs by eliminating rework and enabling the implementation of clinical management in health organizations. In this sense, the municipalities are working toward the full implementation of electronic medical records, which help connect the services and optimize care management ${ }^{(17)}$. At the time of data generation, the studied municipalities were initiating use of the e-SUS system, an online system of the Unified Health System; however, data show they still need to qualify computerization and software and, consequently, more adequately manage referral and counter-referral records.

This situation triggers the debate on the need to qualify the way in which the health system has been organized to meet the needs of users with chronic illnesses. The dependence of users on primary care services and their difficulty in getting medium and high complexity care call attention to the ethical and political commitment of health managers to find alternatives that meet health demands. The Family Health Strategy must function as part and center of communication with the other health services, which would require the adoption of an effective care model for chronic conditions ${ }^{(17)}$. Management should discuss these elements because the transition of care depends on the interaction of different levels of care and, additionally, the functioning of health care through regionalization, as presented in the results of this study

In view of the advancement and complexity of chronic illness and the connection between those who need care and those who provide care, it is disturbing to find that the municipalities cannot fully expand the provision of primary care ${ }^{(3-5.8)}$. This problem seems to be linked to two movements that have been presented together; on the one hand, the persistent difficulty in changing the care model still centered on specific campaigns and actions for traditional populations, which prevents care from adapting to the needs of users with chronic illness. On the other hand, empirical data based on the testimonies of municipal managers show that funding obtained by the municipal health department and coordination still focuses on expanding medium and high complexity care, thus reaffirming the findings in the medical literature ${ }^{(1)}$.

Moreover, empirical data indicate that the reduced work hours of health teams and the inconstant flow of referrals between the municipalities impair the creation of bonds with chronically ill users and organized and planned health actions. This context indicates the still current challenges of primary care ${ }^{(4)}$ since users need to feel welcomed and cared for during the transition of care, especially those with chronic diseases ${ }^{(19)}$. Furthermore, health workers must cope with the persistent issue of not having an established referral and counter-referral system, which weakens the transition from $\operatorname{care}^{(19)}$.

Interestingly, there is a regulation system for medium and high complexity referrals, but two of the studied 
municipalities are under full management (still adopted by the State), considering one is a city and the other shows this management is an obstacle to tending to the health needs of its citizens. Despite the system, medium complexity care has become a bottleneck in the system that impairs health planning and, consequently, the organization of referrals and counter-referrals, which are essential for chronically ill users. In Rio Grande do Sul, most specialized consultations occur in the capital and they are funded by the state government.

The challenge in collective health care is transitioning care in a scenario that does not adapt to assist chronically ill users and has a limited capacity to promote health and prevent diseases due to factors such as the unstable establishment of public policies ${ }^{(1,3-5,8)}$.

\section{口CONCLUSIONS}

Based on the empirical data and the debate proposed here, it was possible to achieve the objective of analyzing the transition of care in the context of chronically ill users and the need to regionalize municipal planning. The studied municipalities show regional actions should be considered for chronically ill users in order to promote care transition strategies and enable the relationship of municipalities based on Regionalized Municipal Planning.

Coordination is essential for the regionalized provision and transition of health care, considering the municipalities need to communicate among themselves and share their installed capacity in the Health Region to meet the demands of chronically ill users. The data reveal obstacles to the organizational flow of chronically ill users in the studied region.

In quest of optimized and shared resources, regionalization is still considered difficult to implement in the Unified Health System, thus generating a significant flow of people from one municipality to the other due to the installed capacity in health care. Managing the health network for chronically ill users is still debatable in the studied municipalities, as well as the way they have managed to shift care among themselves and among care levels in the same territory. The results show the insufficient provision of areas where managers can discuss these topics and indicate the need to consolidate available spaces for dialogue, such as the Inter-management Committees, to enable effectively integrated planning.

The studied scenario - one of the Health Regions of Rio Grande do Sul - demonstrates the still persistent obstacles that affect health care for NCDs reflected in the trajectory of users in the system, thus weakening the transition of care. The municipalities face obstacles due to scarce investments, lack of planning, and disjointed communication.

The limitations of this study are the non-inclusion of more municipalities in which to interview managers of the health units and the lack of references on the transition involving primary care. This study instigates thought on the proposed subject and its relevance for health care.

\section{Q REFERENCES}

1. Almeida PF, Medina MG, MCR Fausto, Ligia Giovanella L, Bousquat A, Mendonça MHM. Coordenação do cuidado e Atenção Primária à Saúde no Sistema Único de Saúde. Saúde Debate. 2018; 42(spe 1):244-60. doi: https://doi. org/10.1590/0103-11042018s116

2. Presidência da República (BR). Decreto nº 7.508, de 28 de junho de 2011. Regulamenta a Lei no 8.080, de 19 de setembro de 1990, para dispor sobre a organização do Sistema Único de Saúde - SUS, o planejamento da saúde, a assistência à saúde e a articulação interfederativa, e dá outras providências. Diário Oficial da União. 2011 jun 29;148(123 Seção 1):1-3.

3. Costa NR. Brazilian healthcare in the context of austerity: private sector dominant, government sector failing. Ciênc Saúde Coletiva. 2017;22(4):106574. doi: https://doi.org/10.1590/1413-81232017224.28192016

4. Campos GWS. Defending the SUS depends on advancing health reform [Editorial]. Interface. 2018;22(64):5-8. doi: https://doi.org/10.1590/180757622017.0772

5. Malta DC, Duncan BB, Barros MBAB, Katikireddi SV, Souza FM, Silva AG, et al. Fiscal austerity measures hamper noncommunicable disease control goals in Brazil. Ciênc Saúde Coletiva. 2018;23(10):3115-22. doi: https://doi. org/10.1590/1413-81232017224.28192016

6. Reuter CLO, Santos VCF, Bottega CG, Roese A. Monitoring practices in municipal healthcare management and their interface with nursing. Rev Gaúcha Enferm. 2016;37(esp):e2016-0019. doi: https://doi.org/10.1590/1983-1447.2016. esp.2016-0019

7. Coelho APC, Larocca LM, Chaves MMN, Felix JVC, Bernardino E, Alessi SM. Healthcare management of tuberculosis: integrating a teaching hospital into primary health care. Texto Contexto Enferm. 2016;25(2):e0970015. doi: https:// doi.org/10.1590/0104-07072016000970015

8. Cecilio $L C O$, Reis AAC. Notes on persistent challenges for basic health care in Brazil. Cad Saúde Pública. 2018;34(8):e00056917. doi: https://doi. org/10.1590/0102-311X00056917

9. Hesselink G, Flink M, Olsson M, Barach P, Dudzik-Urbaniak E, Orrego C, et al.Are patients discharged with care? a qualitative study of perceptions and experiences of patients, family members and care providers. BMJ Qual Saf. 2012;21(Suppl 1):i39-49. doi: https://doi.org/10.1136/bmjas-2012-001165

10. Weber LAF, Lima MADS, Acosta AM, Marques GQ. Care transition from hospital to home: integrative review. Cogitare Enferm. 2017;22(3):e47615. doi: https:// doi.org/10.5380/ce.v22i3.47615

11. Kind AJ, Jensen L, Barczi S, Bridges A, Kordahl R, Smith MA, et al. Lowcost transitional care with nurse managers making mostly phone contact with patients cut rehospitalization at a VA hospital. Health Aff (Millwood). 2012;31(12):2659-68. doi: https://doi.org/10.1377/hlthaff.2012.0366

12. Coleman EA.; Boult C. American Geriatrics Society Health Care Systems Committee. Improving the quality of transitional care for persons with complex 
care needs. J Am Geriatr Soc. 2003;51(4):556-7. doi: https://doi.org/10.1046/ j.1532-5415.2003.51186.x

13. Guerrero KS, Puls SE, Andrew DA. Transition of care and the impact on the environment of care. J Nurs Educ Pract. 2014;4(6):30-6.

14. Minayo MCS. 0 desafio do conhecimento: pesquisa qualitativa em saúde. 12. ed. São Paulo: Hucitec; 2010

15. Ministério da Saúde (BR). Resolução nº 466, de 12 de dezembro de 2012. Diretrizes e normas regulamentadoras de pesquisas envolvendo seres humanos. Diário Oficial da União. 2013 jun 13;150(112 Seção 1):59-62.

16. Ribeiro M, Albuquerque IMN, Cunha ICKO, Mayorga FDO, Neto FRGX, Silveira NC. Organização do cuidado às condições crônicas na atenção primária à saúde de Sobral-CE: avaliação de processo na perspectiva de gestores. APS Rev. 2019;1(1):29-38. doi: https://doi.org/10.14295/aps.v1i1.5

17. Mendes EV. 0 cuidado das condições crônicas na atenção primária à saúde: 0 imperativo da consolidação da estratégia da saúde da família. Brasília, DF: OPAS; 2012 [cited 2019 Apr 12]. Available from: http://bvsms.saude.gov.br/bvs/ publicacoes/cuidado_condicoes_atenca__primaria_saude.pdf

18. Silocchi C, Junge JR. Equipes de atenção primária: dificuldades no cuidado de pessoas com doenças crônicas não transmissíveis. Trab Educ Saúde. 2017;15(2):599-615. doi: https://.doi.org/10.1590/1981-7746-sol00056

19. Silva-Rodrigues FM, Bernardo CSG, Alvarenga WA, Janzen DC, Nascimento LC. Transitional care to home in the perspective of parents of children with leukemia. Rev Gaúcha Enferm. 2019;40:e20180238. doi: https://doi.org/10.1590/19831447.2019.20180238

- Corresponding author:

E-mail:kpena@hcpa.edu.br 